\title{
Inclusive prosperity in South Africa
}

\section{Mark Steeves reports on why politicians do still matter in the 21st Century}

The 2019 Investing in African Mining Indaba was held in Cape Town, South Africa from 4 to 7 February. It was the $25^{\text {th }}$ annual indaba and coincided with the $25^{\text {th }}$ anniversary of the achievement of democracy in South Africa. This fact was noted by South African President Cyril Ramaphosa in a speech he made to conference, a speech in which he proposed that mining companies strive to realise a set of value-creating principles to achieve a more modern, successful and productive mining industry.

Ramaphosa is the first South African President ever to address the Indaba, a remarkable fact given that South Africa has developed as a country against the backdrop of the mining industry. It is also a measure of Ramaphosa's understanding of the whole picture and attention to detail that he chose to make his address to the Indaba, shortly before his State of The Nation Address.

The annual Mining Indaba in Cape Town is one of the most popular conferences in the industry calendar. I can see why. Cape Town in February offers sunny summer days in stark contrast to the weather left behind by visitors from the north. My presence there was as an advisory board member of Moshe Capital Proprietary, a Broadbased Black Economic Empowerment (B-BBEE) black women-owned corporate advisory and investment firm based in Johannesburg, whose strap line is Inclusive Prosperity.

These are not hollow words for Moshe Capital. Nor are they for ordinary South Africans. But the outside world, as well as potential investors in South Africa, seem sometimes not to understand the challenge or appreciate its importance. So, I was gratified that President Ramaphosa's stirring speech reminded the conference of the reasons for black economic empowerment, why it is justified and how it can be achieved.

\section{On mining}

Ramaphosa emphasised that mining in South Africa is a sunrise industry and that unemployment and poverty in the country cannot be meaningfully reduced without increased investment in critical areas of the economy-particularly the productive sectors, of which mining is a vital part. He said, "As government we regard the mining industry as a key player in the future growth and development of our economy, with huge potential for exploration, production and beneficiation..."

As a critical part of the Economic Stimulus and Recovery Plan announced in September 2018, the government is acting to rapidly finalise the Mining Charter and clarify the Mineral and Petroleum Resources Development Amendment Bill.

\section{On land reform}

Ramaphosa acknowledged concerns regarding the expropriation of land without compensation, suggesting that the government aims to enhance property rights and address what they term "the original sin committed against black South Africans during colonial and apartheid days". He assured investors that land would not be taken from them and applauded mining companies with surplus land that had given it up for

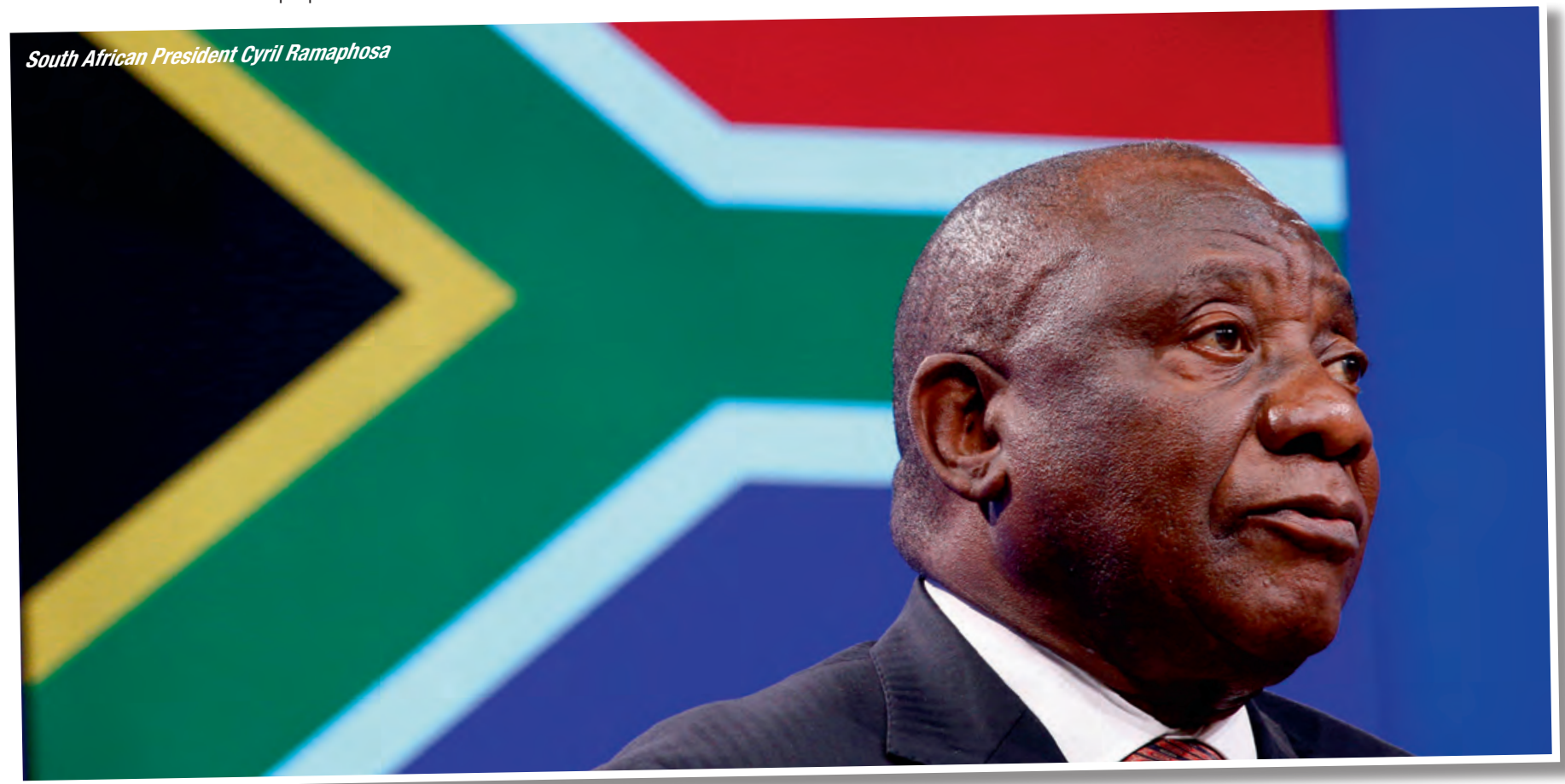




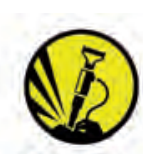

MINING INDABA

2019

housing to local government or for farming to various communities.

\section{Ten principles}

To achieve a more modern successful and productive mining industry, Ramaphosa emphasised 10 value-creating principles, which state that companies should or must: 1) foster inclusive growth in the areas where they operate; 2) partner with local governments to improve infrastructure, such as water and roads, in the areas where they operate; 3) see investment in the living conditions of their workers as more than a regulatory obligation; 4) invest in education and training; 5) partner with training colleges, contributing to the development of curricula and providing work experience for students; 6) embrace beneficiation, processing deposits in-country to increase their value; 7) pay more attention to, and invest more in, the health and safety of workers; 8) provide internships and job experience opportunities for young people-as well as provide business opportunities for Small, Medium \& Micro Enterprise Businesses (SMMEs); 9) prioritise the development of young women, through proactive hiring policies, prioritised training, promotion and mentorship; and 10) have the courage to include their workers in the shareholding of the companies.

People want to know about and be involved in things happening around them, so Ramaphosa urged companies, government and labour to work together to create shared value and ensure that mining benefits are widespread. He stressed that social investment can help end the dehumanising effect of the migrant labour system and, on beneficiation, Ramaphosa argued that this approach not only expands South Africa's industrial capacity, creates employment and increases mineral wealth, it also creates demand and locates markets for the products closer to the production site.

\section{Mining and politics}

It's good to hear mining talked of as a sunrise industry. But South Africa-Africa generally-is resource rich and industry is always going to be interested, as long as resources are in place. What changes are the market forces and political, fiscal, social and regulatory circumstances with which an external investor has to contend. So, for all the fine words offered by President Ramaphosa, the circumstances in South Africa remain uncertain and challenging - at least until South Africa's General Elections on 8 May this year to elect a new National Assembly and new provincial legislatures, which will determine who becomes the next President.

When Jacob Zuma was outmanoeuvred and obliged to resign his Presidency last February 2018, the business community had great expectations from the new President. But now these high hopes and euphoria, dubbed Ramaphoria, have been replaced by predictions of Ramageddon and Ramaruin. I don't know whether that

sort of hype, one way or the other, is justified or to what extent. But, I think Ramaphosa's words and the manner in which he delivers them are worth noting. This is the man who helped launch the South African National Union of Mineworkers in 1982, who has been an important figure in the African National Congress since the dying days of Apartheid South Africa, who headed the negotiating team that brought about

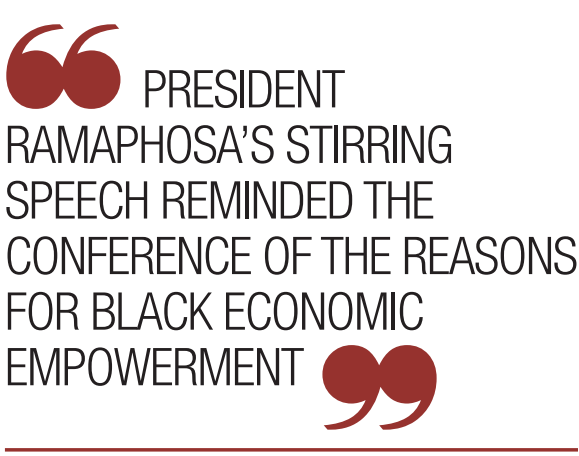

the modern South African democracy, and who since then has become a successful businessman in his own right. It seems clear to me that this man knows what he's talking about, and how to pitch it, whether he's talking to the general electorate, or to a mining conference.

On land reform, for instance, the headline statistic is that while making up $78 \%$ of the population, only $1.2 \%$ of rural land and $7 \%$ of formally registered property in towns and cities is owned directly by black South Africans. The whole story is more complicated but Ramaphosa needs the outside world to understand that there is a genuine issue that must be addressed.

As to his ten value-creating principles, who can have a problem with any of these? Would that the history of mining in the UK had been as inclusive, beneficent and visionary as South Africa's might yet be!

Mark Steeves, Samphire \& Associates Ltd, sits on the City of London Geoscience Forum and Corporate Affiliates Committee. E-mail: MS@SamphireAssociates.com

\section{FURTHER READING}

- Highlights of President Cyril Ramaphosa's speech: https://www.youtube.com/ watch?v=dWX_1rpbf08.

Read or view the full speech at: http:// www.thepresidency.gov.za/speeches/ address-president-cyril-ramaphosa-investingafrican-mining-indaba\%2C-internationalconvention or https://www.youtube.com/ watch?v=dk7ZCEDrOKc 